\title{
Optimization of clonal micropropagation of Chrysanthemum
}

\author{
I. Borodulina ${ }^{1}$, A. Trufanova ${ }^{1}$, G. Shevchenko ${ }^{1}$, G. Sokolova ${ }^{1}$, T. Plaksina ${ }^{2}$ \\ ${ }^{1}$ Altai State University pr. Lenina 61, Barnaul, 656049, Russia. E-mail: borodulina.irina@gmail.com \\ ${ }^{2}$ Federal State Budget Scientific Institution Federal Altai Scientific Centre of Agro-BioTechnologies \\ Nauchnyy gorodok, 35, Barnaul, 656910, Russia E-mail: niilisavenko1@yandex.ru
}

Received 16.10.2019 Accepted 14.12.2019

\begin{abstract}
Micropropagation of Chrysanthemum is an alternative to the traditional method of reproduction. Thanks to this method, the Chrysanthemum reproduction time is reduced to 3-4 months. For clonal micropropagation, sterile microshoots of Chrysanthemums of the varieties Snow White, Stranger, and Baltica White were used. At the stage of the micropropagation, the Murashige-Skoog (MS) medium with the full and half composition of mineral salts and growth regulators (kinetin, 6 -benzylaminopurine, $\beta$-indolylacetic acid) were used. A universal culture medium for clonal micropropagation of all varieties of Chrysanthemum and optimal mediums, taking into account variety-specificity were established. It was noted that under in vitro conditions, high proliferative activity was observed in Neznakomka variety.
\end{abstract}

Key words: Clonal micropropagation; Chrysanthemum; Reproduction; Microshoots

\section{Introduction}

The floriculture industry has become one of the most important branches of agriculture. The largest producers of flower and decorative crops are currently the Netherlands, Poland, USA, Japan, Italy, Germany, Belgium and Canada, and the main consumers are Germany, USA, France and the UK (Getu, 2009). In Russia, the demand for new plants is growing in order to use them for internal and external gardening. Therefore, the problem of mass reproduction of annual and perennial ornamental and flower crops becomes relevant (Timofeeva, Nevmerzhitskaya, 2012). Decorative Chrysanthemums are one of the first flower crops on the world market (Teixeira da Silva, Kulus, 2014). They have been cultivated for over 2000 years. Currently, in Japan alone, there are more than 15000 varieties of Chrysanthemums (Datta, 2013). Traditional methods of propagation of Chrysanthemums do not satisfy the needs of the market. Biotechnological methods are widely used in the propagation of Chrysanthemums in an in vitro culture, as evidenced by numerous publications (Datta, 2012; Deein et al., 2013a, b; Kolomiets, Malyarovskaya, 2013; Kulus et al., 2013; Kuritskaya et al., 2016; Lim et al., 2012; Shinoyama et al., 2006; Teixeiria da Silva et al., 2013; Tymoszuk A., Zalewska M., 2014; Zhou et al., 2014). Biotechnological methods of clonal micropropagation of Chrysanthemums are quite expensive. Therefore, reducing the time of growing Chrysanthemums to a product standard is an urgent problem. An important aspect is to reduce the cost of production of planting material without changing its quality. The purpose of our research is to increase the efficiency of clonal micropropagation of Chrysanthemum.

\section{Material and Methods}

Research was conducted at the Altai Center for Applied Biotechnology of Altai State University. For propagation, three varieties of Chrysanthemums from the in vitro collection were used: Snow White and Neznakomka (Korean Chrysanthemum), Baltica White (Indian Chrysanthemum). For clonal micropropagation of Chrysanthemum, the induction process of adventitious and axillary shoot formation was used. The explants were microcranes with a leaf and axillary kidney. Explants were grown in flasks on eight variants of culture mediums (Table 1 ).

Table 1. Variants of culture medium for clonal micropropagation of Chrysanthemum.

\begin{tabular}{llc}
\hline No & \multicolumn{1}{c}{ The composition of the culture medium } & $\mathbf{n}$ \\
1 & MS (the control) & 15 \\
2 & MS + Kn $1.0 \mu \mathrm{M}+\mathrm{IBA} 0.2 \mu \mathrm{M}$ & 15 \\
3 & $\mathrm{MS}+\mathrm{BA} 1.0 \mu \mathrm{M}+\mathrm{IBA} 0.2 \mu \mathrm{M}$ & 15 \\
4 & $\mathrm{MS}+\mathrm{Kn} 1.0 \mu \mathrm{M}+\mathrm{IBA} 0.2 \mu \mathrm{M}+\operatorname{agar} 4.0 \mathrm{~g} \mathrm{~L}^{-1}+\operatorname{starch} 20.0 \mathrm{~g} \mathrm{~L}^{-1}$ & 15 \\
5 & $0.5 \mathrm{MS}($ the control) & 15 \\
6 & $0.5 \mathrm{MS}+\mathrm{Kn} 1.0 \mu \mathrm{M}+\mathrm{IBA} 0.2 \mu \mathrm{M}$ & 15 \\
7 & $0.5 \mathrm{MS}+\mathrm{BA} 1.0 \mu \mathrm{M}+\mathrm{IBA} 0.2 \mu \mathrm{M}$ & 15 \\
8 & $0.5 \mathrm{MS}+\mathrm{Kn} 1.0 \mu \mathrm{M}+\mathrm{IBA} 0.2 \mu \mathrm{M}+\operatorname{agar} 4.0 \mathrm{~g} \mathrm{~L}^{-1}+$ starch $20.0 \mathrm{~g} \mathrm{~L}^{-1}$ & 15 \\
\hline
\end{tabular}

The cultivation of Chrysanthemum microshoots was carried out under the following conditions: light mode - 16/8, illumination 3000 lux, temperature $-24 \pm 1^{\circ} \mathrm{C}$. The growth and development of regenerants was evaluated on day 30 of cultivation. Statistical data processing was performed using the Microsoft Office Excel 2010 software. The arithmetic mean, arithmetic mean error, confidence interval, and Student t-test values were calculated at $P \leq 0.05$. 


\section{Results and Discussion}

In our experiments, active proliferation of adventitious and axillary shoot formation was observed in the fourth and eighth variants (Figure 1). The reproduction coefficient in the control was $4.3 \pm 0.6$, in the fourth and eighth variants were $3.8 \pm 1.1$ and $4.2 \pm$ 0.9 respectively.

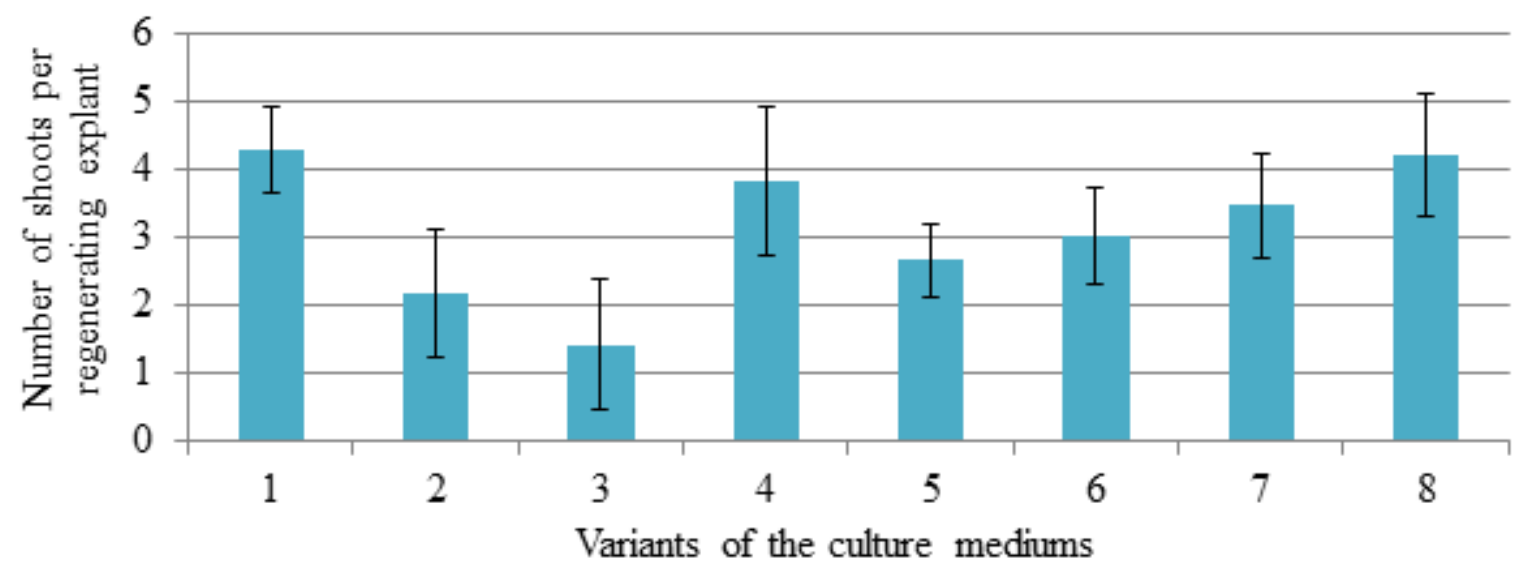

Figure 1. The reproduction rate of Chrysanthemum in vitro culture.

In general, a decrease in the mineral composition of culture mediums (variants 5-8) had a positive effect on the regeneration of Chrysanthemum. milar results were obtained, E.V. Kuritskaya et al. (2016) during the propagation of microprobes of the East Asian species of Chrysanthemum Chrysanthemum leiophyllum. Optimal for this variety was the MS medium with half the content of mineral salts. The maximum reproduction rate $(5.4 \pm 1.3)$ was recorded in the variety Snow White on the fourth variant of a culture medium with a complete composition of mineral salts. It was 4.5 times higher than the same indicator in other variants. Varieties Neznakomka and Baltica White, on the contrary, had maximum reproduction rate (4.4 \pm 0.7 and $5.1 \pm 0.9$, respectively) in the eighth variant of the culture medium with half the composition of mineral salts. Thus, in our studies, the variety-specificity of Chrysanthemums during clonal micropropagation was confirmed, which is also noted in the works of Granda Hamillo (2009). The height of Chrysanthemum microshoots in an in vitro culture varied depending on the composition of the culture medium (Figure 2).

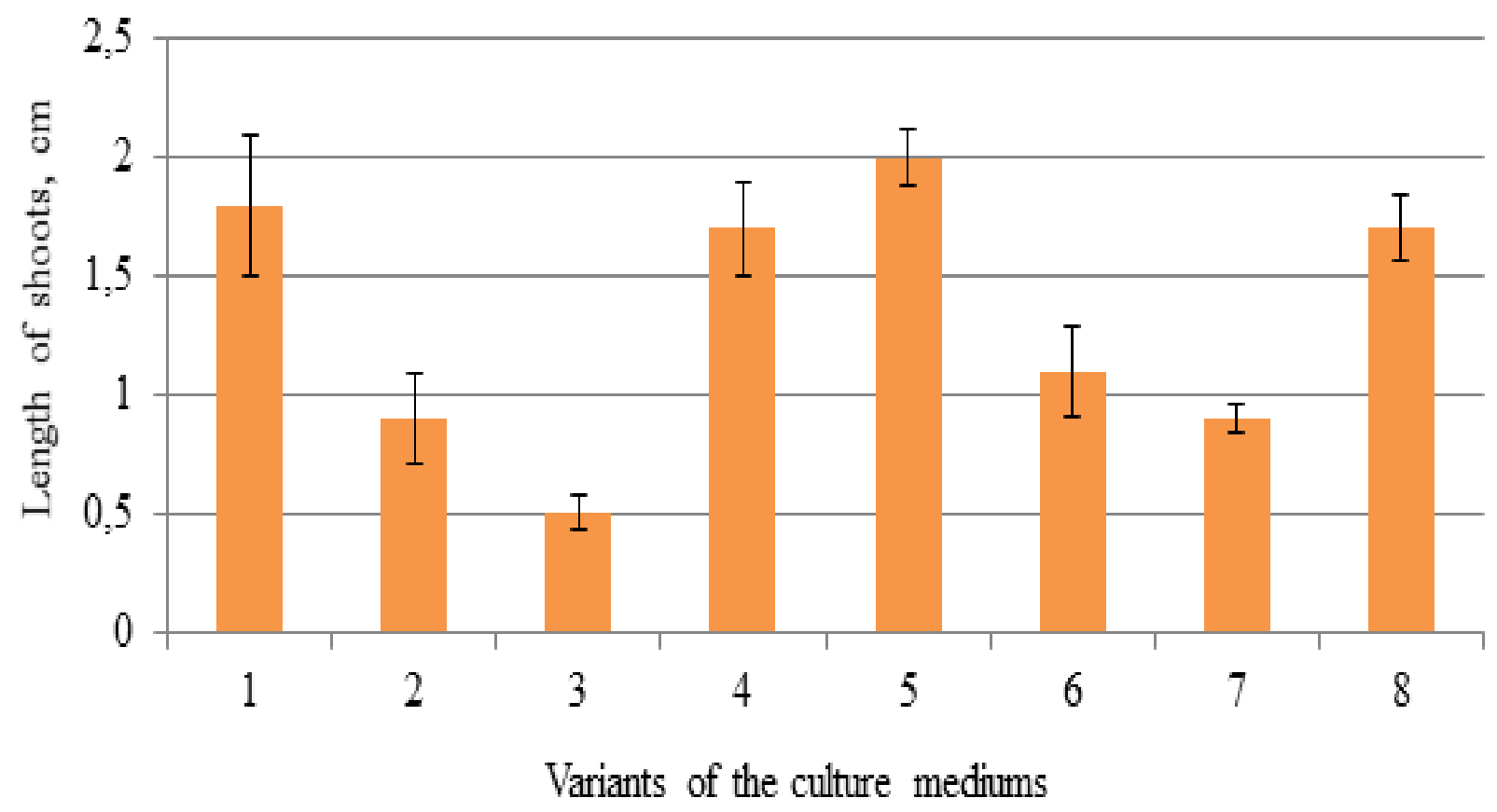

Figure 2. Chrysanthemum shoot height in vitro culture.

In our experiments, larger microshoots with a height of about $2 \mathrm{~cm}$ were formed in the control version and in fourth and eighth variants with the full and half composition of mineral salts. On nutrient media with other compositions, the height of the microprobe did not exceed $1 \mathrm{~cm}$ (Figure 3). An important parameter is the foliage of the shoots, which leads to the production of a large number of microshoots and new regenerants. The maximum number of leaves (8.0 $\pm 1.1 \mathrm{pcs} / \mathrm{shoot})$ was formed in the control variant and in the fourth variant. A decrease in the content of mineral salts in the culture medium did not lead to a significant decrease in the leafiness of microshoots. 


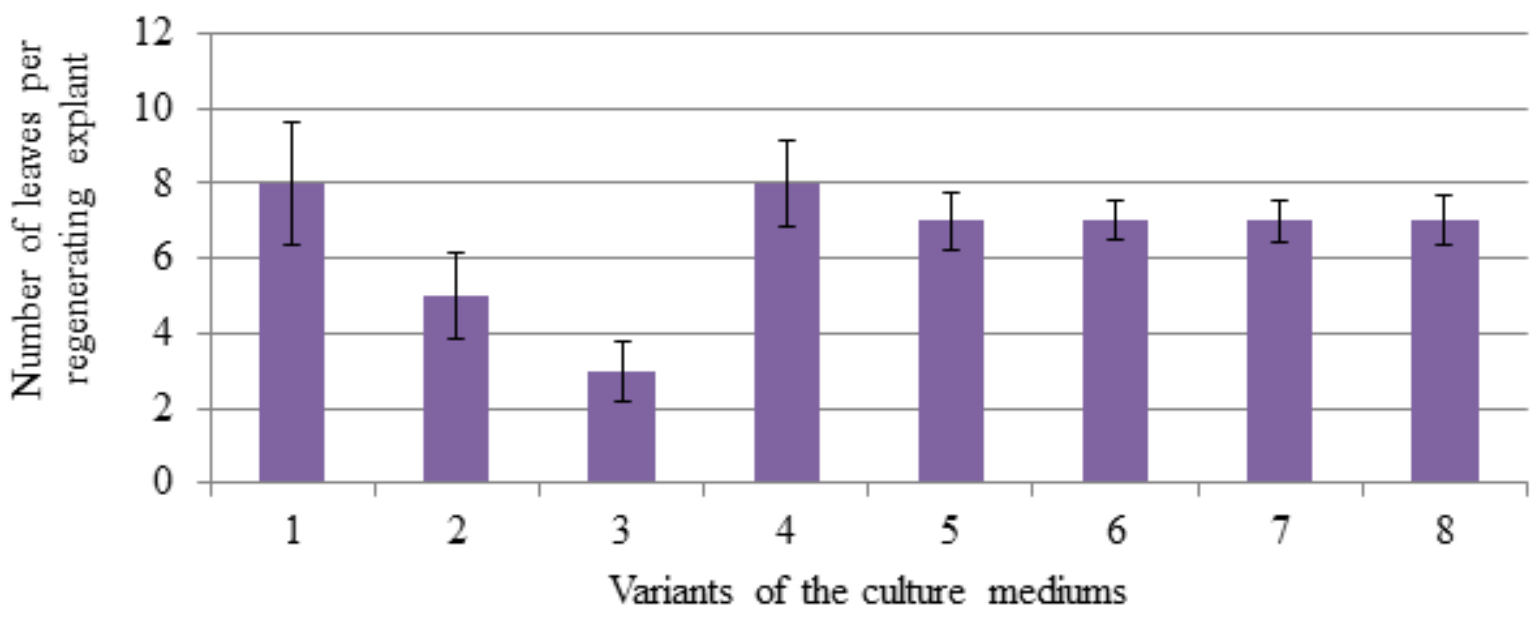

Figure 3. Obligacy of Chrysanthemum in vitro culture.

\section{Conclusion}

The universal culture medium for the clonal micropropagation of Snow White, Stranger, and Baltica White Chrysanthemum varieties is $0.5 \mathrm{MS}+\mathrm{Kn} 1.0 \mu \mathrm{M}+\mathrm{IBA} 0.2 \mu \mathrm{M}+$ agar $4.0 \mathrm{~g} \mathrm{~L}^{-1}+$ starch $20.0 \mathrm{~g} \mathrm{~L}^{-1}$ (variety multiplication factor was $5.4 \pm 1.3,4.4 \pm 0.7$, $5.1 \pm 0.9$, respectively). The optimal culture medium were identified for each variety: for Snow White $-\mathrm{MS} \pm \mathrm{Kn} 1.0 \mu \mathrm{M}+\mathrm{IBA}$ $0.2 \mu \mathrm{M}+$ agar $4.0 \mathrm{~g} \mathrm{~L}^{-1}+$ starch $20.0 \mathrm{~g} \mathrm{~L}^{-1}$; for the Stranger and Baltica White - $0.5 \mathrm{MS}+\mathrm{Kn} 1.0 \mu \mathrm{M}+\mathrm{IBA} 0.2 \mu \mathrm{M}+$ agar $4.0 \mathrm{~g} \mathrm{~L}^{-1}$ + starch $20.0 \mathrm{~g} \mathrm{~L}^{-1}$. Higher proliferative activity is characterized by the Neznakomka variety.

\section{References}

Datta S. K. (2012). Success story of induced mutagenesis for development of new ornamental varieties. In: M. I. Kozgar and S. Khan (eds), Induced Mutagenesis in Grop Plants. Biorem. Biodiv. Bioavail. 6 (Special Issue 1), 15-26.

Datta S. K. (2013). Chrysanthemum morifolium Ramat. - a unique genetic material for breeding. Sci. Culture, 7-8, 307-313.

Deein W., Thepsithar G., Thongpukdee A. (2013a). In vitro culture medium sterilization by chemicals and essential oils without autoclaving and growth of Chrysanthemum nodes. World Acad. Sci., Engir. Technol., 78, 1038-1041.

Deein W., Thepsithar C., Thongpukdee A. (2013b). Growth of Chrysanthemum explants on MS medium sterilized by disinfectants and essential oils. Int. J. Biosci., Biochem. Bioinformatics, 3(6), 609-613.

Getu M. (2009). Ethiopia floriculture and its impact on the environment. Regulationg, Supervision and Compliance. Mizan Law Rev, $3(2), 242$.

Granda Hamillo R.K. (2009). Mikroklonal'noe razmnozhenie hrizantem. Izvestiya TSKHA, 1, 145-148 (in Russian).

Kolomiets T.M., Malyarovskaya V.I. (2013). Usovershenstvovanie biotekhnologicheskih priemov polucheniya vysokokachestvennogo posadochnogo materiala hrizantemy. Subtropicheskoe i dekorativnoe sadovodstvo, 48, 115-122 (in Russian).

Kulus D., Mikula A., Zalewska M. (2013). Cryopreservation: an efficient tool to combat genetic erosion phenomenon in agriculture and horticulture. IVth International Scientific Symposium for PhD Students and Students of Agricultural Colleges - Innovative researches for the future of agriculture and rural areas development, Bydgoszcz, 61.

Kuritskaya E.V., Nedoluzhko A.I., Vrzhosek E.V., Boltenkov E.V. (2016). Klonal'noe mikrorazmnozhenie Chrysanthemum leiophyllum (Asteraceae). Turczaninowia, 19(2), 99-104 (in Russian).

Lim K-B., Kwon S. J., Lee S. I., Hwang J-Y., Naing A. H. (2012). Influence of genotype, explant source, and gelling agent on in vitro shoot regeneration of chtysanthemum. Hort. Environ. Biotechnol., 53(4), 329-335.

Murashige, T., Skoog, F. (1962). A revised medium for rapid growth and bioassays with tobacco tissues cultures. Physiologia Plantarium, 15(13), 473-497.

Shinoyama H., Anderson N., Furuta H., Mochizuki A., Nomura Y., Singh R. P. et al. (2006). Chrysanthemum biotechnology. In: Floriculture, Ornamental and Plant Biotechnology: Advanced and Topical Issues. Global Science Books, Ltd., Isleworth, UK, 140163.

Teixeira da Silva J. A., Shinojama H., Aida R., Matsushita Y., Raj S. K., Chen F. D. (2013). Chrysanthemum biotechnology: Quo vadis? Critical Reviews in Plant Sci., 32(1), 21-52.

Teixeira da Silva J. A., Kulus D. (2014). Chrysanthemum biotechnology: discoveries from the recent literature. Folia Horticulturae, 26(2), 67-77.

Timofeeva O. A., Nevmerzhitskaya Yu. Yu. (2012). Klonal'noe mikrorazmnozhenie rastenij. Kazan. Publishing house of Kazan University (in Russian).

Tymoszuk A., Zalewska M. (2014). In vitro adventitious shoot regeneration from ligulate florets in the aspect of application in Chrysanthemum breeding. Acta Sci. Pol., Hortorum Cultus, 13(2), 45-58.

Zhou Y., Wang Y. Y., Song Y. R., Gao Z. Y., Liu Y. M., Fan L. J., et al. (2014). Stem apex detoxification culture mark edly improved several physiological characters of Chrysanthemum "YUTAI". Plant Cell Tissue Organ Cult., 119, 369-381.

\section{Citation:}

Borodulina, I., Trufanova, A., Shevchenko, G., Sokolova, G., Plaksina, T. (2019). Optimization of clonal micropropagation of Chrysanthemum. Ukrainian Journal of Ecology, 9(4), 676-678.

(cc) $\mathrm{EY}$ This work is licensed under a Creative Commons Attribution 4.0. License 